\title{
Behavioral disorders in adolescents and Orthodontics Attitude of orthodontists? How far to go?
}

\author{
M.-C. Thery-Hugly
}

Oral Surgeon, Behavioral Psychologist

Former University Hospital Assistant, Lecturer Paris VII Member

of the National Academy of Oral Surgery

President-Founder SPOM-IFA Plus

\begin{abstract}
Adults are often worried and somewhat shocked by teenagers' behavior, and their way of learning, the so-called "Adolescence Disorders."

The lack of assertiveness of adolescents is the most important issue in the management of orthodontic treatment. With the desirable attitude of empathy in mind, for the majority of teenagers, the orthodontist will manage treatment in a quiet and optimal way.

For $15 \%$ of them however, real problems such as anxiety, depression or personality disorders may appear. The use of CBT will be useful.

The orthodontist must be empathetic enough to guide these young teenagers in their development, through their "mouth," this organ is psychologically invested to fundamental symbols of life and learning.
\end{abstract}

\section{KEYWORDS}

Psychology, Cognitive Behavioral Therapy, Orthodontics, Adolescents

\section{INTRODUCTION}

\begin{abstract}
"Teens" are "teens," as children are children, as the elderly are elderly. But this state is peculiar, both in the short and long term, both an end and a beginning, evolving, with a mixture of both children and adult characteristics. In short, adolescents have their own way of functioning, their fears, worries, desires, hopes and education, which
\end{abstract}

are called "teenage troubles," can worry adults who feel a bit helpless.

The lack of self-assertion in adolescents is the behavioral disorder that can pose the biggest problem to the orthodontist in managing orthodontic and dentofacial (DFO) treatment.

Provided that the desired behavior of empathy, consideration, and firmness is taken into

\section{Address for correspondence:}

Marie-Claire Thery-Hugly - Les Petites Vignes - 11

route de Villeneuve - 89320 Vaumort

E-mail: marieclaire@hugly.fr

This is an Open Access article distributed under the terms of the Creative Commons Attribution License (http://creativecommons.org/licenses/by/4.0), which permits unrestricted use, distribution, and reproduction in any medium, provided the original work is properly cited. 
account, in the majority of adolescents, the orthodontist will manage the treatment in a therapeutic alliance in a calm and optimal way. On the other hand, in $15 \%$ cases, real problems can appear.

Moreover, in adolescents as in the general population, anxious, depressive, or personality disorders can exist and give this period of life a distinctive tone.
The orthodontist, whose treatment will cover this period of preadolescence and adolescence, will have an important role in guiding these young patients in their development, their evolution, through their "mouth," which is an organ so psychologically invested in fundamental symbols of life and learning.

\section{THERE ARE COMMUNICATIONS WITHOUT LANGUAGE AND LANGUAGES WITHOUT COMMUNICATION}

\section{Deborah, 16, shackled by braces}

A lady comes to consult me from the countryside, sent by her dentist, to talk to me about her 16-year-old daughter.

Over the last two years, all of her daughter's teeth have appeared. The multi-fasteners were laid in one session. According to her mother's statement, it was during the second consultation to the orthodontist. Was the first visit a diagnostic consultation? Everything is pretty vague.

The fact is that because this multifastener placement session, Deborah has refused any oral care whatsoever. She rejects the idea of these foreign bodies in her mouth, and even refuses an intervention to have her braces removed. No one can touch her, not her mouth, nor the rest of her body, not even her doctor.

She continues to brush her teeth and tests them because she feels them moving, she is convinced that they move around, that she will lose them. In exhausting nightmares, she dreams that her teeth are falling out.

She no longer likes the way she looks, nor the way others look at her.
For the last two years, she has hardly left her house. Apart from high school hours, where she still has to goes out of necessity, she remains isolated. She does not go on vacation any more, in any case never without her parents and her sister. She is terrified of losing her family, her house, her belongings. And everything that touches her body, her teeth of course but also her hair, she cannot stand the idea of cutting her hair. She refuses to express herself.

She is nevertheless a brilliant student who studies alone and by correspondence. Her parents and teachers support her but are completely helpless. They took their daughter to a psychologist who has been following her for a year. Deborah is just beginning to talk to him.

The next consultation, Deborah who agreed to meet me, accompanied, rather "brought" by her mother, is "gently" calm but totally opposed to any treatment.

They come from far away, I make this effort and speak with Deborah.

This was the beginning of a rich and forward-looking relationship of a year 
of office appointments and then correspondences.

What do you think? How would you approach a case like Deborah's? We will decipher this case and its outcome a little later on.

\section{Solaine, preteen, who vomits everywhere!}

In the waiting room, 12-year-old Solaine, withdrawn into herself, looking at her feet, looking both stubborn and absent, does not flinch when I come to get her. It is her parents who practically push her into my office.

I sit in front of her, my face at her level, I take both hands in mine, I catch her eyes.

- Solaine, why are you coming to see me?

The parents are nearby, silent and motionless.

- Why have you come to see me?

- I don't know.

- How old are you Solaine?

-12 .

- Ah, that you know. Where are you?

- At the dentist.

- So maybe you've come here for me to take care of your feet?

- I'm barely cheering her up! No, my teeth.

- Good, and what should I do to your teeth?

- The orthodontist said, "You hurt your teeth. Your teeth need to be extracted!"

Solaine begins to splutter with tears.

- Solaine, look at me.
I take her face in my hands, I look into her eyes, I smile at her:

- Solaine is that really what she told you, or is it what you thought would happen?

Silence... The parents are becoming more and more tense, anxious and frustrated.

- That's what I thought she meant, she said in a very small voice.

- Now I understand! The parents start talking:

"For the past year, we've been around dentists who want to extract her teeth, she's had these terrible panic attacks. Solaine screams, struggles, vomits, you know what it is like a young person who is afraid, who has a stomach ache the days before the appointments, who does not sleep anymore? She says her orthodontist is "horrible"; look at the condition of her teeth (indeed this preteen, cute if not, has a class II occlusion and a significant dentomaxillary disharmony (DMD), we could not start any orthodontic treatment, and anyway, Solaine does not want us to even mention Dr. X, her orthodontist! » I ask them, "And you, do you know why Dr. X talked about extracting Solaine's teeth?" No! The intelligent, open-minded father and the nurse mother who has heard of "softer methods" and who wanted to try again, do not know why "they have to extract their daughter's teeth!" Clearly, there was a lack of adequate communication between Dr. $\mathrm{X}$, the young patient and the parents, who were probably very anxious at the time and in an exacerbated state of anxiety at the thought of this intervention. For the past two years, orthodontic work has 
been on-hold and if we do not reestablish a relationship, it will never take place.

We will also analyze these different behaviors and the care of Solaine.

\section{Kevin and Lola, the happy twins}

\section{Kevin, to continue to eat well}

- Since when do you have DFO treatment?

- Approximately 2 years ago. I started with my palate and now I have my braces.

- Why do you have this treatment?

- Because my teeth were out of place.

- Did it bother you that your teeth were out of place?

- No... personally...

- Did you notice that they were misplaced?

- No, I only knew when the orthodontist explained to me how bad my teeth were.

- Was it embarrassing, aesthetically?

- No, it was not embarrassing, I didn't feel anything, and no one could see them.

- So how was it embarrassing that they were misplaced? In what way was it better that they were well placed?

- They did not fit together properly.

- Why, for you, was it embarrassing when no one could see them?

- Yes, I had trouble chewing.

- Are you sure? I didn't realize it.

- Since my teeth didn't fit together properly, from time to time there were foods that I couldn't chew.

- You then understood why and accepted that you needed a device for this inconvenience, even though you didn't think it was a big deal. Has it changed anything now that you can bite into things with your incisors?
- No, it hasn't changed my life particularly.

- You have undergone this treatment for the last few years just for that reason?

- It's also so that when I'm older, my teeth stay in place, are more secure and I can continue to eat well.

- Did your orthodontist explain it to you? How does it work? With X-rays?

- Yes, with panoramic X-rays.

- And what do you do to ensure the treatment works?

- I support it well.

- Do you mind having to brush, paying attention to what you eat, cleaning the palate every morning, it bothers you?

- No, it's just that you have to be careful.

- Do you know how long your treatment will last?

- I think it will last another year or two.

- Was it your orthodontist who explained all that to you? Well done!

\section{Lola, to be beautiful}

- How old are you Lola?

$-12$.

- How long have you had your treatment?

- Since the end of fifth grade, approximately 2 years ago.

- Why did you have this treatment, Lola?

- To have beautiful teeth, straight teeth, and later have a beautiful smile.

- So, for aesthetic reasons?

- Yes.

- Did your teeth bother you?

- Yes, I did not dare smile because my teeth were crooked.

- How were they crooked? 
- The front tooth had turned a little!

- They were not quite aligned with others? Nothing else bothered you?

- No.

- It bothered you a lot?

- No.

- Did you ask for orthodontic treatment?

- No, my dentist suggested it because my teeth were not aligned well. The ones from the top and the ones from the bottom a little bit.

- Who explained it to you?

- The orthodontist told me that I would need a false palate to spread the jaw so that after we can put in braces to align the teeth and make them straight. After they fitted a night-time device.

- How did you react to the device, the braces?

- Well!

- And what about the constraints, not eating sweets, cleaning... all that...?

- No, no, that's okay.

- Have you ever had pain?

- No, never.

- You don't mind smiling at your girlfriends, do you? No, it does not bother me and then there are plenty of friends who also have braces.
- And what about smiling at boys?

- No. Not too much...

- What does that mean?

- I mean, no, I mean, I smile normally. I don't think about it too much.

- I am happy to see that your orthodontist has explained it to you well, that you have understood it well, that you are very satisfied with life and your orthodontic treatment.

Kevin and Lola express in their answers the two main reasons for orthodontic interventions: functional and aesthetic, they understand and support their treatment perfectly.

The prescribing oral surgeon, the empathic orthodontist, the pre-teens and the accompanying parents are all involved, consistent, and in a perfect therapeutic relationship.

We will see how, too.

It's a safe bet that in a year or two, these two DFO treatments end up technically, relatively, and psychologically successful for these two teens.

It must be recognized that the cases of these twins, whose father had also benefited from a successful orthodontic treatment, are more common in DFO practices.

\section{CAN WE UNDERSTAND TEENS?}

\section{"Private" rites of passage 8}

Adolescence "worries" most adults. Parents, teachers, caregivers, public servants, politicians, all seem to take the same look at this "population" that is baffling in its behavioral manifestations, its troubling behavior, its worrying silences... or its unprecedented aspirations.

An impression that it is time to fight does not reflect the reality?

Do teens need to be understood? Even though they do not understand themselves yet... 
Do we, as adults, really remember this period?

Have we erased the "painful memories," the "vertiginous states of mind" and the radical questioning of this crossing of the ford between childhood and adulthood?

"Adolescence" is all of our representations of this age group caught between two states.

Patrice Duette defines it as follows: "Adolescence is the term that characterizes our inability to make an individual go from being a child to being an adult! But this was not the case recently in our Western societies, and this is still not the case in so-called primitive societies, which offer initiatory rites."

In fact, if puberty is the defining event that brings young people into adolescence, "adolescence" does not exist in itself, in an immutable way.

"Adolescence is a period during which the young person builds their personality, develops their sexuality, and becomes autonomous. On the other hand, over time, it is directly linked to the society's view of puberty issues and the proposals made to them to attain adult status."

Before the middle of the 19th century, there was no adolescence, "puberty" signified access to a new status and responsibilities in adult society, via well-defined modalities of passage: religious, military, or other. In addition to changes in the body, puberty corresponded to the evolution in rights: "pubertas" from which the word "puberty" comes from. This meant, as it does today physiologically, the legal age of marriage. Body and law went hand in hand.
This vagueness and variability of the term adolescence, these uncertain frontiers of preadolescence and postadolescence, reinforce young people in their identity disorder while they are only looking for ways to enter adulthood.

The collective rites of passage to adulthood, ${ }^{8.9}$ such as those observed in traditional societies, no longer exist in the West. Only a few important events persist, such as the first sexual encounter or reaching 18 , first summer jobs, diplomas, etc.

Teenagers invent the private rites that gradually make them enter the world of adults themselves.

Certainly, for the majority of young people, the transition to adulthood does not cause many difficulties. They are built progressively by experimenting with the world and others. To grow, the young person forges personal myths and builds small meaningful stories. Tattoos or piercings, music, daydreams, the complexity of a diary or a blog, communication techniques are milestones that allow the transition to adulthood.

But for others, $15 \%$ of them, the pain of living is more important, and some young people go further: They defy death to prove that they exist in a society that ignores them, to prove they have their own value if they cannot read it in the eyes of others, to mobilize their self-esteem, and to give meaning to their lives.

"Without being in any way nostalgic of the primitive rituals of passage, it is clear that the path for initiation was 
clearer on the island of Pentecost when it was about jumping from $25 \mathrm{~m}$ in the air wearing a liana on each ankle, than causing a scooter accident while drunk on the way home from a party! In the first case you are part of the "insiders," in the second case of you are treated as accident victims, delinquents, and other "immature people." 4,5

Therefore, "self-initiation" replaces the absence of initiatory rites in our societies: The risk- taking and "self-sabotage" of many adolescents.

Remember that accidents and suicides are the two leading causes of death among young people! There is also, in many cases, acute alcoholism, scarification, running away, and dropping out of school.

\section{TEENAGE TROUBLES}

How many young people are anxious, hyperactive, depressed, addicted to drugs, or feel bad in their own skin? What will be the consequences of the disorders they suffer? Can we predict or prevent the consequences?

Epidemiological studies in adolescents are particularly difficult to interpret: risk factors (which are not causes) can be identified for various mental disorders, it is not possible to specify the number of patients.

The individual capacities of teenagers in the midst of physical and psychological changes are put at risk by many stressful events.

The risks of maladjustment are high and can lead to feelings of helplessness or difficulties resulting in either of the following:

\section{When and how can one come out of childhood and become an adult?}

For lawyers, there are two categories: minors and adults.

For physiologists, there are several benchmarks: the age of bone maturation and that of the brain.

For all others, parents, educators, caregivers, psychologists: Is it getting a diploma? A driving license? Or gaining indepencence (financial independence and housing)?

More and more pre-teens and teens are coming into the orthodontist's practice.

As if orthodontic treatment became the rite of passage for our teens?

Externalized problems: when the young person has little control over themselves: impulsiveness, aggressiveness, attention problems, hyperactivity, violence, etc.

Internalized problems: withdrawal, anxiety, depression, anorexia, loss of self-esteem.

\section{The depressed teenager}

Approximately one in four young people think of suicide. But not all are depressed in the clinical sense of the term: risk-taking, opposition, and withdrawal are "normal" maturation processes $^{8}$.

Depression and malaise in adolescents are two different disorders that are difficult to distinguish. 
Unlike the adult, the depressed adolescent is often agitated, very active, and takes risks, but they are constantly devaluing themselves.

When the adolescent is really depressed, follow-up is advised and sometimes the prescription of psychotropic drugs is necessary. Anti-depressant drugs decrease the risk of suicide.

\section{Self-esteem, self-assertion}

People with low self-esteem often have difficulty asserting themselves: saying no, giving their opinion if the other person has a contrary opinion, etc. ${ }^{3}$

This is especially true for teenagers!

Learning to develop one's self-assertion allows one to find a fair level of self-esteem.

Development of one's assertive state involves,

- being able to express who we are, what we love, what we believe, what we think, what we are entitled to, what we feel without fear and in a legitimate way about people and the environment;

- expressing oneself calmly, without hesitation and in a constructive way;
- having confidence in oneself, to face situations in life, even in delicate ones, which force us sometimes to take firm or unpopular positions;

- gradually regaining control of one's personal environment: asserting one's identity, rights, tastes, ideas, thoughts, feelings.

To be assertive,

- is to adopt an attitude that is neither passive nor aggressive;

- is to express as directly as possible what we think, what we feel, and what we want, while taking into account, of course, what the other person thinks, feels, and wants;

- is also about acting in accordance with one's own interests and upholding one's rights, without infringing on the rights of others.

For children and adolescents, whether assertive or assertive, the concept is the same.

A teenager's lack of assertiveness is the behavioral disorder that will be the most problematic for the orthodontist in managing a treatment.

\section{RECOGNIZE THEIR POTENTIAL AND LET THEM GROW}

Our adult fear of the next generation is hidden behind the appearance of benevolence, and every effort is made to delay the maturity of adolescents.

\section{In this context, what would teenagers need?}

- Already, not to be considered freaks who are nothing like previous generations! They are just like adults were when they were younger!

- Also, do not confuse changes of form (ways of being, musical tastes, clothing, etc.) with the basic constants (the questions of identity and their value as a person).

- They also need adults, to both understand and oppose them! 
And above all they need recognition of their value and their abilities by an invested adult, in this case by the caregiver during care!

"Basically, according to Michel Fize, there is no necessary opposition between adults and adolescents. But there are seven essential needs to satisfy: need for trust, need for dialog, need for security, need for autonomy, need for responsibility, need for affection, and need for hope" 4 .
Orthodontists have all the tools that we will detail to respond favorably to these seven critical needs, while remembering that the teenager, even one willing to cooperate with their care, will oppose the world of adults, parental authority, and that of the practitioner, which is normal.

On the other hand, aggressive, stubborn, or passive-aggressive refusal of care or dental hygiene can be a disguise of hostility.

\section{DFO (Dentofacial orthodontics): A LONG-TERM TREATMENT AT AN AGE OF IMPATIENCE AND LEARNING AND SEDUCTION}

The aim of DFO in children is to promote a harmonious development of the face, by intercepting or treating abnormalities that appear early, decreasing the risk of dental trauma.

In adolescents, DFO treats established abnormalities with special attention to facial aesthetics and optimal function.

The devices, whether fixed or removable, can be the source of all kinds of problems because of their inconvenience and their aesthetics. The discomfort will always be there, less or more severe, intermittent or long-term. Aesthetics can be improved.

The reported inconveniences, related to the devices, occur at several levels:

- chewing pains during meals;

- functional discomfort, speech difficulties in the first few years;

- embarrassment with hygiene requiring extra care in brushing teeth, much more frequent visits to the dentist;

- an aesthetic embarrassment and this is the most important problem, that of the mockery of others, therefore of the way others look at it. And "the others" represent everyone: classmates, teachers, friends, parents themselves, siblings, and family too.

At the age of ten and then in adolescence, social dependence is very strong and peer acceptance plays an extremely important role in psychological development.

Children are often unable to appreciate all the implications of their derogatory remarks. Yet, a child or adolescent who is rejected or becomes the object of curiosity and sarcasm to their peers will soon isolate themselves; their psychosocial development may even be somewhat affected.

C. André and F. Lelord (1999) ${ }^{1}$ talk about the parental pressure and that of their peers:

"There are four main sources of significant judgments for a child and four sources of self-esteem: Their parents, teachers, peers, and friends. During 
adolescence, the movement that pushes parents back as the main provider of self-esteem gradually increases in favor of people outside the family circle."

It's easy to see how a teenager with all their doubts, frailties, and self-esteem can be affected and have their psychological development affected.

In fact, in DFO treatments, there are many incidents because of poor self-expression by adolescents who do not know how to assert themselves: who may become inhibited, or refusing, or aggressive!

Especially because they are at the age when they are still shy and unsure about their personality, the teenager sees, "the orthodontic appliance" as a huge handicap to their love life!

Another psychological responsibility for the orthodontist, but by this means also the opportunity to motivate them, we will explore this further.

\section{The mouth is a symbolic place of all the evils and all the words}

Although the orthodontists' main concerns were first of all diagnosis and treatment, they have always been aware of the psychological implications of dentofacial dysmorphoses.

The face, mouth, and teeth play a very special symbolic psychological role in psychological balance, in interpersonal, intimate, and sexual relationships as well as in psychosocial development.

Dentofacial dysmorphoses can cause many emotional reactions ranging from simple discomfort to complete social withdrawal, accompanied by deep feelings of inferiority and strong anxiety reactions.

And the paradox is that by intervening with the mouth, the main organ of communication with the outside world, the orthodontist will modify the very expression of communication, improve it, or hinder it during the care or as a later result of it.

A person's speech can sometimes be altered, there are aesthetic changes, a readjustment needs to be made regarding the person's self-image.

In short, we disrupt, momentarily or permanently, the relationship, and social balance of an adolescent already undergoing change and adaptation.

\section{THE ORTHODONTIST'S ATTITUDE. HOW FAR CAN WE GO?}

For Voizot (1993), "it is by an attitude of expectation, a provocative language, or an assurance that leads the teenager to share the orthodontist's views. They see themselves change, they no longer feel like a child but are not yet an adult. Their parents and teachers don't understand them, and they don't really understand themselves. Each of us remembers being more than once surprised by the brutal growth and changes during our youth. A few months ago, there was a boy who was still clearly a child, and now we find ourselves in the presence of someone who has suddenly grown up and we do not know how to approach them. In a situation of care, the relationship with 
the adolescent must take into account the changes that occur so that the remedial actions take place in good conditions"19.

\section{A suitable behavioral relationship ${ }^{13}$}

One must always think that yesterday's mode of relationship still shapes the type of relationship of today. In our status as family odontologists, an adolescent's consultation is built up by childhood consultations. To know the peculiarities of the teenager and to be attentive to what is said, what is done, what is not said, what is communicated, the odontologists/orthodontists should make extra efforts in the period when parents and children consult together on the condition, so that the quality and strength of the medical bond can be maintained.

"The impact of parental approval is still significant and really begins to diminish only when the young person leaves their family," says André.

Especially in dentofacial orthopedics, treatment is most often started on young, preadolescent patients, who are therefore very emotionally connected to their parents, who are highly influenced by them and under their legal and financial responsibility; the relation is therefore a three-fold relationship: parents, practitioner, and teenager.

In this triangular relationship, each protagonist influences the other. Treatment should only be started in a situation of relational agonism. It must always be remembered that cooperation accounts for $80 \%$ of successful orthodontic treatment. Few medical treatments require as much cooperation. The "therapeutic complicity" and even the "therapeutic alliance" between the orthodontist and their patient are not only a reality but a necessity.

\section{An empathic behavioral therapeutic style ${ }^{18}$}

Regardless of the stage of intervention-i.e., whether during the scheduling of appointments, at the reception, during the first appointment, during the explanation of the treatment, during the implementation of the collaboration procedures, during the follow-up of the collaboration, to the end of the treatment, during the wearing of braces - the quality of the communication, and therefore the therapeutic relationship, should satisfactory. This will ensure the adherence to the treatment plan, persistent motivation, good compliance, and financial and administrative follow-up. In short, it is the rapid success of treatment which is as rewarding for the practitioner as it is for both the parents and the affected children ${ }^{15}$.

On the contrary, an average communication, and therefore an average therapeutic relationship, can stumble at the slightest incident or misunderstanding. ${ }^{14}$ It is then that treatments get postponed or abandoned, because of the poorly supported and delayed techniques, the family's disinterest in treatment, the loss of cooperation, and/or the gradual or abrupt abandonment of treatment.

The goal is to establish a relationship, a mutual collaboration between the practitioner, the adolescent, and the parents.

The first consultation ${ }^{10}$ allows us to perform a functional analysis of the patient, to collect the data necessary 
for the diagnosis-including technical, behavioral, and psychological data-to establish a treatment plan adapted to this patient.

This is the evaluation: the classical clinical examination accompanied by an assessment of the patient's motivation, their parents, their relationship with their parents and the social context, their friends, and also the adolescent's level of self-esteem and self-affirmation. The practitioner looks at the patient, listening intently they agree, it is primarily their nonverbal language that will encourage the patient to "open up," and express themselves.

The practitioner does not interrupt the patient and speaks only when they have stopped speaking, the practitioner's attitude becomes more active: They ask questions about their reasons for consultation, their desires.

Why? Most of the time the patient is so engrossed in their problem, in their emotions that they will talk a lot about their hopes or their fears but will not really give the orthodontist the elements they need to inform, reassure, and heal the patient.

The practitioner shows interest in the patient. This question-and-answer stage is very important, it's the functional analysis, the situation will become clearer. The practitioner's reformulation: It will focus on the patient's emotions, desires, and then the problematic situation as a mirror effect.

The rest of this consultation, there should be a motivational mini-interview ${ }^{11}$ with Socratic questioning:

-The orthodontist makes the patient verbalize their request. All the ambivalence is there, the patient is questioning, but they are also asking.
- It is their request and their freedom to be treated "Yes, I came to get treatment because..."

- Then follow open-ended questions that characterize empathy: "What can I do to help you? "Do you have an idea?"

- The statement must come from the patient. It is therefore the search for solutions in a collaborative way.

The practitioner gives them back control, the patient will bring up solutions, this way they will adhere to it, they will have their say, it is a therapeutic contract.

The therapeutic alliance is therefore established in an empathic way when presenting the treatment plan to the teenagers and their parents.

The role of the practitioner is defined but also that of the patient and the parents throughout the treatment.

Checking results at each session, using positive reinforcement, is an opportunity to maintain motivation.

Showing empathy involves ${ }^{18:}$

- listening to your patient: asking open questions, actively listening, with patience;

- show understanding: rephrasing the emotion felt, the situation that makes them anxious;

- help them find a suitable solution: through psychological support, Socratic questioning, and active search for personalized solutions.

The consequences on the patient are as follows: a confidence gained by the practitioner, the verbalization of worries with a return of control, treatment acceptance, a positive memory, the building of a long-term relationship with perpetuation of the practitioner-patient relationship, and the significant decrease in the risks of refusal of care and uneasiness. 
Empathy is the first attitude to have that allows the patient to take a step back and feel at ease and helped. It is an effective and forward-looking methodical behavior to help the majority of patients, regardless of their problems.

\section{Positive reinforcement and motivation}

Orthodontic treatments are longterm treatments, lasting 2-3 years or more, with visits at intervals, with temporary intermissions. The young patient can find the timeframe a little long; if they are not very motivated, they may lose patience.

Commitment, therapeutic contract, mutual agreement, and compliance with instructions are essential for maintaining motivation.

When considering the results of orthodontic treatment, it is observed that the failures are due more often to a lack of patient cooperation. On the contrary, the great results are associated with excellent patient motivation.

One motivational method is knowing how to express a positive message and practice positive reinforcement. The idea of punishment should be dismissed and do not hesitate to express satisfaction: "Wonderful, you're right on time. It would help me if everyone was like you!"

"Well done! I notice that your teeth are particularly well brushed now: Look in the mirror. There is more plaque on the collar and this has been the case for several weeks because the gums are a beautiful pale pink."

\section{Cognitive behavioral therapy (CBT), learning, self-control}

CBTs are based on behavior learning theories from experimental observation. ${ }^{6}, 11$; They are effective because there is an interaction between behaviors, emotions, and cognitions.

The focus is on the actual causes of problem behavior, rather than on unconscious causes.

Sustainable change in behavior is considered a major criterion for successful therapy.

Treatment procedures are objectively described and reproducible by other therapists for patients with similar difficulties.

\section{Caroline, 18, ashamed that she still sucks her thumb}

Caroline, 18 years old, comes to our consultation because she still sucks her thumb, she doesn't want to but can't stop.

Her parents tried everything to stop her, bitter nail polish, gloves at night, reprimands, rewards, nothing worked, and the idea of orthodontic treatment was even abandoned with bitterness a few years ago.

Until now it did not bother her too much, but now she has a boyfriend and she is ashamed in front of him! She absolutely wants to stop.

Functional analysis revealed that Caroline sucked her thumb especially at times when she was tired, coming home from school, falling asleep, or 
when she was bored in front of the $\mathrm{TV}$, or when she was upset, or anxious while doing her homework. It calmed her, but also gave her pleasure thanks to the taste of her thumb in the mouth, the smell, and the feel of it.

The clinical examination also revealed a significant interposition of the tongue.

The functional analysis, performed using self-checks, along with an awareness of the various behavioral problems analyzed cognitively in an effort to identify a patient's emotional state, constitute an important stage of care.

Empathically, a strategy has been put in place: we will first solve the problem of the thumb, then the interposition of the tongue.

Caroline had learning exercises to do every day in full consciousness. She must have been "surprised" not to have a thumb in her mouth, or later to have her tongue in a good resting and swallowing position She practiced self-checking records at times, determined together, with final "victory" scores from 0 to 20 .

Analysis of the self-check records at each consultation allowed for positive reinforcement and cognitive restructuring.

In parallel, we had looked for what could replace the pleasure of sucking her thumb: It was a glass of her favorite juice. (Later she told me that the pleasure of kissing her boyfriend was just as good!)

Every day, she had to do mindful relaxation to work on stress and anxiety.

After two months, the thumb problem had been resolved; four months later, the interposition of the tongue had also been fixed. The support appointments were gradually spaced out when the desired results were acquired.

Caroline wanted to start an orthodontic treatment.

\section{Self-affirmation and self-esteem in DFO}

A clinical study was performed on adolescents who underwent DFO by G. Ballet $^{2}$ in 2003, for a memoir of the DU of TCC (Paris V).

A self-affirmation scale for children and adolescents was used: the Rattus scale adapted by F. Petit, V. Mahama, $R$. Bore, to evaluate the degree of selfassertion of adolescents.

Self-assertion deficits can be found in many psychiatric pathologies, but the scale is most often used as the first tool for screening for unasserted behavior in other anxiety disorders, certain chronic depressions, stressrelated pathologies, etc.

The results showed that:

- in the preadolescent period, most subjects exhibited a lack of assertiveness;

- in adolescence, the trend is much higher.

This study made it possible to better understand the personality of the teens to whom we will propose orthodontic treatment, to anticipate if possible their crises, their doubts, and their anxieties.

Assertiveness through the scale we have used makes it quite easy to situate the patient in their own context, apart from their ubiquitous parents in our exercise.

Then individual or group psychological work makes it easier to accept the 
orthodontic period for patients with impaired assertiveness.

The orthodontist may be at this time a "revealer" for these patients who in any case will have to be helped.

It would be desirable for other studies to be carried out on the same group two years after this work.

The first conclusions we must draw are to study patients outside the norms, that is to say the passive and aggressive patients, because they are the ones who will pose the most problems during orthodontic treatment.

We can distinguish very significant periods:

- in girls, age 10-11 years: passive tendency; age 15 years: passive tendency, aggressive upsurge at age 14 years and 16 years;

- in boys, age 13 years: passive tendency; at age 14, 15, 18 years: aggressive tendency.

These are exactly the periods in which the orthodontist theoretically intervenes.

\section{Patients failing assertiveness $(<103.5$ on our scale)}

They have very backward attitudes in certain situations:

- difficulty expressing opinions;

- require more evidence of their value compared to others;

- incapacity:

- of initiative,

- of dialog and decision-making,

- of oral expression,

- to get out of a situation,

- to express themselves,

- to express one's own opinion,

- to talk,

- to be guided by others.
The orthodontic appliance, visible or embarrassing, can only reinforce an already existing attitude.

\section{Patients with an excess of asser- tiveness ( $>125$ on our scale)}

Similarly, attitudes are exacerbated in affirmation and aggression, or even the kind of "band leader." The orthodontic appliance may be refused and even deliberately broken.

\section{What can we learn from this?}

If necessary, is it already possible to make the wearing of an orthodontic appliance more aesthetically pleasing?

- It can be made as unobtrusive as possible (transparent) or when the dysmorphias allows it, a removable device that only needs to be worn at night.

- The position in terms of lingual vs. palatine; but this will not solve the problems (speech and a teenager's first kiss).

- Deferring in time by modifying the treatment sequences: young preventive action, and limited adult action?

Can we then imagine working or having worked in collaboration with a psychologist, an assessment of adolescents' assertiveness before any treatment?

Groups of teenagers for assertiveness training are already being used in certain districts of Paris. This idea might be useful for DFO treatments!

\section{Anxious patients}

The prevalence of anxiety disorders in the general population is $30 \%{ }^{17}$. 
$80 \%$ of respondents say, in their own words and with varying degrees of intensity, that they are stressed and anxious to go to the dentist.

Anxiety, as we have seen, is part of the spectrum of adolescent disorders.

The orthodontic treatment lasts a very long time and as a result we find ourselves in the pubertal period and the children we started to treat have become worried teenagers.

Many teenagers may be worried, anxious, at the idea of receiving care. They need help, not only for themselves, but also in relation to treatment. They may not keep appointments, cancel appointments, or stop treatment.

Anxiety in the orthodontist's office is therefore a real problem that must be taken into account.

To best help the anxious patient, we must first be able to identify them ${ }^{18}$.

Some signs are recognizable, posture, nonverbal elements that are immediately significant:

- avoidance of gaze, slouching, arms crossed, closed attitude;

- apparent muscle tension in the body and face (mouth, jaw), clenched hands;

- general agitation, excessive perspiration, sweaty hands, changes of position showing discomfort;

- hyperventilation, dry mouth, fast heart rate.

Certain behaviors must alert the practitioner and the assistant to the patient's degree of anxiety ${ }^{14,17,18}$.

- The patient seems impatient.

- They are irritable and react sharply.
- They are hypersensitive, their senses are heightened, and they jump at physical contact.

- They are aggressive, in their gestures and the tone they use.

- They are clumsy. They bump into things and seem disorientated and lost.

- They avoid questions.

Elements of dialog are characteristic.

They cannot stand the wait before the treatment, it makes them nervous.

- They show signs of nervousness when the practitioner mentions certain treatments.

- They talk about memories or possible complications by developing scenarios.

- They seek reassurance.

- They ask a lot of questions.

- They constantly anticipate, in an anxious manner.

- From a benign technical term, thy come up with disaster scenarios.

Once the patient's fear is identified and recognized, the practitioner can act. If the practitioner refuses to acknowledge it or underestimates it, they risk the patient refusing the care.

However, there are solutions to help these young people who are suffering:

- empathy is the first and most important thing with these patients;

- then implement CBTs such as relaxation and desensitizing the patient to instruments and medical procedures.

These are simple gestures and attitudes, which can be easily learned for the well-being of patients and the profession! 
The orthodontist can also get help and collaborate with a psychologist or psychodontologist.

\section{Depressed adolescents}

Depression is known to be a common disorder in the general population: $10 \%-20 \%$ will suffer it at some point in their life, and even more so in cohorts of health care seekers.

We have seen how much depression and uneasiness in adolescents can be characteristic of this period.

For the practitioner, the first step is to recognize depression before being able to propose an appropriate relationship, treatment, and care ${ }^{12}$.

Not knowing the mode of functioning of the depressed patient and disregarding this state can lead to a breakdown of the therapeutic relationship.

The patients are sad, have no pleasure in life, and live without desires; their speech is overwhelmingly negative, and feel they have no purpose in life.

\section{The depressed patient's mouth}

The young person will disinvest in the entire orofacial sphere by inhibiting all valorization and self-esteem, as they do not care about their body or social life.

Usually, dental hygiene will be inexistent or inadequate, creating a kind of "vicious circle"18: the dental state deteriorating as a result of this defective hygiene and deterioration of the dental state aggravate the depressive state of the patient, thereby promoting an absence of brushing; hence, the observation of periodontal disease and cavities is required.

\section{Psychological support by the CBT of the depressed patient in the dental office ${ }^{17}$}

Empathy. once again the essential behavior, without an excess of optimism, without an excess of distance (not wanting too much involvement can be interpreted as a lack of interest), without excessive concern expressed by the practitioner.

Comprehension. the absence of judgment, explicit or implicit, on the part of the practitioner is what the adolescent is expecting. Even if today depression is less associated than formerly with a negative social judgment (lack of will, of moral strength, carelessness), it must be remembered that it is in some way a guilt illness, lack of oral hygiene or abandonment of dental care, where the patient sees his or her self-esteem collapsing.

Positive reformulation. Depressed people are affected by judgments of values or pessimistic thoughts. The practitioner can then use positive reprogramming: It is not a psychotherapeutic technique in the proper sense and cannot durably modify the mood of a depressed person, but it is a robust factor in creating a strong therapeutic relationship. The positive reformulation gradually allows the dentist to influence the way in which their depressed patient perceives and verbalizes their difficulties: It is a question of helping them to bypass their overall negativity and create specific shortterm objectives. 


\section{Give specific benchmarks}

- Propose a simple treatment plan, possible to achieve in short steps, each in the near future.

- Provide information about the treatment. Each step will be explained by drawing attention to the patient's face, their mouth, objectively explaining to them the positive points of the proposed treatment.

- Involve them in the choice and development of treatment. Reformulation, the active and positive listening, the assurance that you understand is essential for making sure the patient actively participates in their treatment.

- To "show" them and demonstrate, step by step, the positive, functional, comfortable, pleasant or aesthetic achievements of each realization, not only at the level of their mouth, but also more generally and socially; to reassess the patient and reward them.

- At each session, offer the patient simple and precise tasks to measure their progress, at the level of the mouth (hygiene, adaptation stage to a device), but also on the function and the role of their mouth (social life). Make them describe the result and with each small victory,

\section{CLINICAL CASES: EPILOGUES}

\section{Deborah}

Uncommon case of decompensation after DFO treatment shows that the treatment was probably rushed with reinforce it positively, of course, and show them that we care.

- Their mouth, and their relationship with their mouth, can help the patient lead a more dynamic life.

In the face of doubt, or if the patient has not yet been treated for their depression, the odontologist should direct them "gently" to a specialist. From there, a specialized and adapted program will be set up with the collaboration of a psychotherapist.

\section{Many orthodontists pose the question of familiar address versus the teenagers' use of formal address}

Why not take advantage of this familiarity to ask what they prefer: a more formal or informal setting?

We always aim to show empathic self-assertion.

Practice empathy, active listening, positive reformulation, giving and applying a specific treatment plan are effective strategies for behavioral and cognitive therapies.

They are easy to learn and practice, they can be very useful to orthodontists, as well as to all health professionals, allowing for the psychological support of these adolescents in difficulty who are in need of care and who trust them.

an obvious lack of empathy. Deborah had anxiety disorders comparable to post-traumatic stress disorder, separation anxiety, and probably a borderline personality disorder. 
We worked in CBT with her on these anxiety and post-traumatic disorders.

She learned to assert herself. She accepted and followed the treatment plan after 6 months of psychotherapeutic support and we removed her braces (in agreement with the orthodontist, because it was almost 3 years after she had them fitted), she hasn't said if she will ever see her practitioner again! She learned to be independent. Now she is traveling alone from the countryside by train for consultations. Our support lasted 1 year in Paris. Then we met over the internet. She gradually resumed a normal life. Two years later, she is doing very well, has passed her exams successfully, travels alone throughout France and abroad (Britain, Rome, London, Amsterdam, she does not stop), she's cut her hair (!), treats her teeth well, but unfortunately, she did not return for any more DFO treatment, but her sister did!

"Everything is always going very well, the removal of the device made me change and mature, the progress was enormous: I have more confidence in myself, I dare to assert myself and it helps me a lot in my relationships with others and knowing what I want. I have also changed a lot since I had my hair cut..."

"I went to Delft... with friends..."

"My sister will soon have a device fitted..."

"You can see that everything is going well, thanks to your help," and so on.

\section{Solaine}

This scene took place on January 26th in the office of the psychologist-oral surgeon. In April, the four premolars were extracted without any problem, with complete compliance, confidently (Solaine even stayed awake on the chair for the last extraction without anxiolytics!). She has remained in contact with the orthodontist, the treatment will begin at the beginning of the school year.

There was no miracle, the practitioner played the role of both "communicator" and empathic dentist using the CBT techniques and strategies as mentioned above.

At the beginning of the care relationship, empathy and good communication would have been enough to allow Solaine and her parents to follow the treatment plan offered to them with complete peace of mind.

\section{CONCLUSION}

The practice of psychosocial techniques allows us to form an often more accurate evaluation of the pathology and the patient's request. A correct diagnosis and a well-informed request results in an adapted, accepted, and observed treatment plan.
To allow the adolescent to assert themselves, to express themselves, while respecting the rules of the office and requirements of the treatment, through dialog, the identification of their desires, their emotions, an environment adapted 
to their needs, a treatment schedule established with them according to their wishes, with occasional formalities, will help the patient get over their inhibitions and tame any aggressiveness. The chore of the obligatory visit to the orthodontist can therefore become a source of interest and enrichment for their personality.

Our general rule of behavior for this age group will therefore include consideration, responsibility, and firmness.

Conflict of interest: The authors declare no conflicts of interest.

\section{REFERENCES}

1. André C, Lelord F. L'estime de soi. S'aimer pour mieux vivre avec les autres. $2^{e}$ éd. Paris : Odile Jacob, 2008.

2. Baillet G. Affirmation de soi chez des enfants et des adolescents avant appareillage orthodontique. Mémoire de DU de TCC. Paris : Université R. Descartes Paris V, 2001.

3. Fennel M. Traduction Docteur A. Surmonter la faible estime de soi. Paris : Dunod, 2013.

4. Fize M. L'adolescent est une personne. Paris : Éditions du Seuil, 2005.

5. Fize M. Ne m'appelez plus jamais crise ! Parlez de l'adolescent autrement. Toulouse : Érès, 2003.

6. George G, Vera L. La timidité chez I'enfant et l'adolescent. Paris : Ed. Dunod, 1999.

7. Huerre P, Pagan-Reymond M, Reymond JM. L'adolescence n'existe pas, $2^{e}$ éd. Paris : Odile Jacob, 2002.

8. Le Breton D. Une brève histoire de l'adolescence. Paris : Jean-Claude Béhar, 2013.

9. Le Breton D. En souffrance : Adolescence et entrée dans la vie. Paris : Métailié, 2007.

10. Mesnay W, Bourassa M. Orthopédie dento-faciale : Une relation clinique adaptée. RC 1997;8:255-265.

11. Mirabel-Sarron C, Vera L. L'entretien en thérapies comportementales et cognitives, $4^{e}$ éd. Paris : Dunod, 2014.

12. Thery-Hugly MC. Sous la direction de André C et Bery A. Au-delà des dents, le patient. Malakoff : Éditions Scientifiques L\&C, 2003.

13. Thery-Hugly MC. La communication affirmée confortable et rentable au cabinet d'Orthopédie Dento-Faciale. Octobre 1996 ; Ormone 16.

14. Thery-Hugly MC. Approche psychologique de l'enfant et de l'adolescent en chirurgie buccale. RC 1995;6:279-292.

15. Thery-Hugly MC, Todorova I. Relation praticien-patient. Encycl Méd Chir (Elsevier Masson, Paris), Odontologie 23 840-C-10, 1998 : 10 p.

16. Thery-Hugly MC, Hugly C, sous la direction de Girard P, Jeandot J, Quevauvillers J, Perlemuter L. Dictionnaire médical du chirurgien-dentiste. Paris : Masson, 1997.

17. Thery-Hugly MC, Baillet G. Utilité et utilisation des TCC en Odonto-Stomatologie. In : Samuel-Lajeunesse B, Mirabel-Sarron C, Vera L, Mehran F et al. Manuel de thérapie comportementale et cognitive. Paris : Dunod, 2005. 
18. Thery-Hugly MC. " J'aime mon dentiste " "Vaincre mon anxiété sur le fauteuil "; https:// www.pierre-fabre.com/fr/actualites/jaime-mon-dentiste-une-operation-originale-par-pierrefabre-oral-care.

19. Voizot B. L'inquiétude de l'adolescent en situation de soins. Rev Orthop Dento Faciale 1983;17:293-300. 